\title{
Current experience in intraocular fine needle aspiration biopsy in Mexican-Mestizo population
}

\author{
Daniel Moreno-Páramo ${ }^{1}$, Marcelo Baizabal Castro ${ }^{1}$, Fernando Pérez-Pérez ${ }^{1}$, Ivette Hernández-Ayuso ${ }^{2 *}$, Dolores Ríos y Valles-Valles ${ }^{2}$, \\ Leonora Chávez-Mercado ${ }^{1}$ and Abelardo A. Rodríguez-Reyes ${ }^{2}$ \\ ${ }^{1}$ Ophthalmology Service, Ophthalmologist, Retina and Vitreous Surgery Department, Hospital General de México, "Dr. Eduardo Liceaga”, Mexico \\ ${ }^{2}$ Ophthalmic Pathology Service, Ophthalmologist, Ophthalmic Pathologist. Asociación para Evitar la Ceguera en México, I.A.P Hospital "Dr. Luis Sánchez \\ Bulnes", Mexico
}

\begin{abstract}
Background: Since the first intraocular biopsy performed in 1868 [1] by Hirshberg and experience published by Jackobiec in 1979, fine-needle aspiration biopsy (FNAB) in the eye has been used for several intraocular tumors [2].

In developed countries there is wide experience regarding intraocular FNAB, in contrast to developing countries where this diagnostic tool has been left aside.

Aim/Objective: To inform the first number of cases of intraocular FNAB perfomed in Mexican-Mestizo patients of the retina service at the General Hospital "Eduardo Liceaga" in Mexico City.

Material and methods: FNAB were perfomed using general anesthesia. Conjuctival incision at 4 mm from limbus followed by the insertion of a 23 gauge needle attached to a syringe using a connector tubbing. Aspiration of $0.10 \mathrm{cc}$ of undiluted vitreous was realized. After wound closure cryotherapy was applied. Vitreous smears were performed and remaining material processed in a cell block. Preparations were stained with Hematoxylin-Eosine and Peryodic Acid Shiff and evaluated under conventional light microscopy.

Results: There were a total of 7 cases. The histopathological diagnosis were 2 cases of Coats' disease, an intraocular invasive squamous cell carcinoma from the conjunctiva, ciliary body melanocytoma (magnocelullar nevus), acute endophtalmitis, non Hodgkin's lymphoma and amelanotic melanoma. Complications were one retinal detachment and a vitreous hemorrhage.

Conclusions: In difficult cases after the exhaustive clinical evaluation, FNAB becomes a very good choice as a diagnostic tool. In order to minimize serious potential eye complications we strongly advice intraocular FNAB to be performed by trained subspecialists and the microscopic evaluation should be interpreted by an expert ophthalmic pathologist. Althought in our country there is limited experience, first results are encouraging.
\end{abstract}

\section{Introduction}

Hisrchberg performed the first intraocular biopsy in 1868 [1] then Jackobiec published his experience in 1979. Since then fineneedle aspiration (FNAB) biopsy in the eye, has been used for several intraocular tumors [2].

In underdeveloped countries this diagnostic tool has been left aside, because the fear of tumoral seeding in to the needle tract [3], the lack of technology for adequate specimen processing and accurate interpretation.

The accepted indications for intraocular FNAB are 1) Major diagnostic uncertainty, 2) Amelanotic mass in a patient with history of previous non ocular malignancy, 3) Patient refuses treatment until malignancy is confirmed, 4) Suspected re-growth following an intraocular mass, 5) Prognostication is requiered, 6) Patient agree to be included in a scientific study [4], 7) Amelanotic mass in a patient without history of systemic malignancy. About one third of patients with intraocular metastasis ignore they have a primary malignancy elsewher [5]. In this group intraocular FNAB diagnosis could be useful after primary tumor is localizated and treated [6]. For intraocular FNAB Shields et al. reported rates of sensitivity $100 \%$ and specifity $98 \%[7,8]$.

\section{Methods}

According to the declaration of Helsinky, patients from the Hospital General de México "Eduardo Liceaga" retina service with clinical suspicion of intraocular malignancy and doubtful diagnosis were considered candidates for FNAB. In the presence of a potential sigth or life threatening disease without a realiable diagnosis after exhaustive clinical examination, ultrasound, fluorescein angiography and computed tomography evaluation. Informed consent was explained and signed in all the cases.

FNAB was performed in the operating room (OR), keeping aseptic techniques and using general anesthesia. After topical $5 \%$ povidone iodine antisepsis conjuctiva was incised at $4 \mathrm{~mm}$ from the corneo-

Correspondence to: Hernández-Ayuso Ivette, Asociación para Evitar la Ceguera en México, "Hospital Dr. Luis Sánchez Bulnes", Vicente García Torres No. 46, Barrio San Lucas Coyoacán, Ciudad de México 04030, Mexico, Tel. +52 (55)10841400, Fax: +52(55)10841400, E-mail: varitahernandez@hotmail.com

key words: fine needle aspiration biopsy, ocular oncology, ophthalmic pathology, intraocular tumor, primary tumor

Received: March 20, 2017; Accepted: April 21, 2017; Published: April 24, 2017 
scleral limbus. A 23 gauge needle attached to a straight polyethylene connector tubing (12 inches long) to a $10 \mathrm{cc}$ syringe was introduced in the sclera at ciliary body pars plana level. From the syringe $0.10 \mathrm{cc}$ of undiluted vitreous was aspirated (Figure 1). Scleral and conjuctival wounds were closed with 7-00 polyglactin 910 suture (vicryl), followed by 3 spots of cryotherapy. Material from syringe was sent to ophthalmic pathology service immediately. Smears were performed and the remaining material centrifugated for cell block. After fixation in 10\% formalin for 24hrs, paraffin embbeded 4 microns sections were stained with Hemtoxylin- Eosine (H\&E) and Peryodic Acid Shiff Stain (PAS). Subsequent conventional light microscopy evaluation by ophthalmic pathologist.

\section{Results}

There were a total of 7 patiens that underwent intraocular FNAB. Microscopic evaluation revealed 2 cases of Coats' disease (Figure 2), and intraocular invasive squamous cell carcinoma from the conjunctiva, ciliary body melanocytoma (magnocelullar nevus) (Figure 3), acute endophtalmitis, non Hodgkin's lymphoma and amelanotic melanoma. Complications were a case with retinal detachment and another with vitreous hemorrage.

\section{Discussion}

Usually clinical examination with non-ivasive techniques and image studies are enough for the diagnosis of intraocular tumors. However in some cases stablishing accurate diagnosis can be challenging, in these cases FNAB may be helpful. Samples may be obtained via anterior segment, such as aqueous tap, iris and ciliary body through iridectomy and/or iridocyclectomy, and FNAB. Factors evaluated for intraocular FNAB are location, size and clarity of ocular media ${ }^{9}$. Instrumentation in FNAB varies depending the involved tissue (aqueous choroid, subretinal space, retina, vitreous), it is not recommended for lesions less
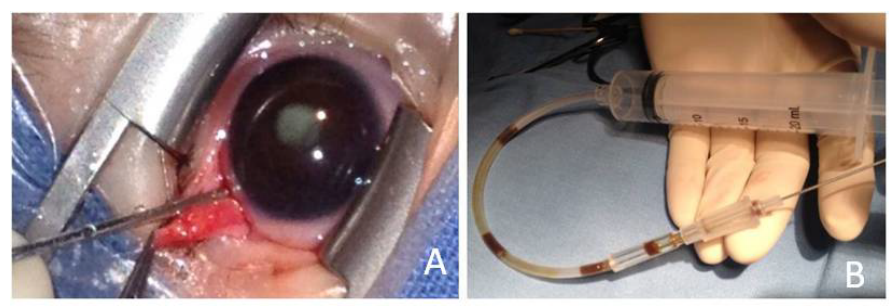

Figure 1. A) Scleral needle insertion (23G) $4 \mathrm{~mm}$ from limbus in the ciliary body pars plana B) Connector tubbing and $10 \mathrm{cc}$ syringe for vitreous aspiration.

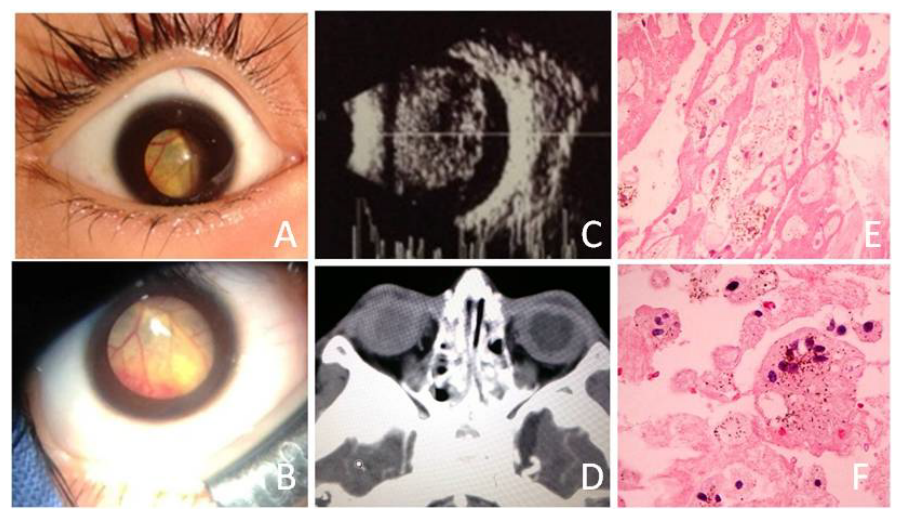

Figure 2. A,B) OD clinical leukocoria C) Ultrasound B-Mode showing an intraocular mass with no evidence of calcification D) Axial computed tomography with OD intraocular isodense occupative mass E,F) Histopathologic features revealed numerous foamy histiocytes and absence of neoplastic cells (Coats' Disease) (H\&E, x20, x40).

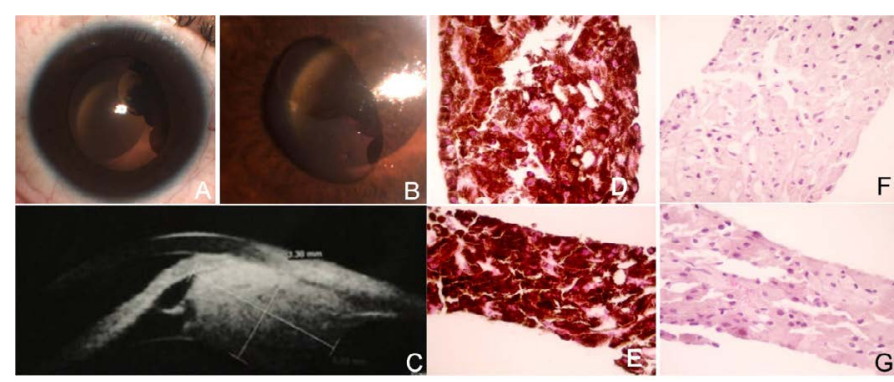

Figure 3. A,B) Pigmented mass behind the iris C) Ultrasound biomicroscopy revealed a ciliary body heterogenic mass with iris anterior displacement $D, E$ ) Histopathologic features showed heavly melanin pigmented cells (H\&E 20x) F,G) Bleached sections revealed uniform bland cells with oval nuclei, no prominent nucleoli and no mitosis were seen (Melanocytoma/ magnocelullar nevus) (H\&E 40x).

than $2 \mathrm{~mm}$ of thickness. Most frequently used needles for ophthalmic FNAB are of 25-30 gauge. Thicker gauge improves the size of the sample compared to a thinner gauge needles. FNAB complications are localized transient vitreous haemorrhage (46\%) [10], retinal detachment (3.7\%) [4], only two endophthalmitis has been reported (Cohen, Faulkner-Jones) [11,12], and malignant cells seeding. There is special concern when retinoblastoma $(\mathrm{Rb})$ is suspected; although there are no reports of extraocular growth of $\mathrm{Rb}$, despite punctures with 25 -gauge or smaller needles $[13,14]$. Theorically thinner needles would carry less risk of malignant cells seeding than thiker ones. If a $\mathrm{Rb}$ is suspected FNAB and vitrectomy are contraindicated. Nevertheles for some authors FNAB is considered a viable diagnostic choice in selected cases of leukocoria when conventional investigative modalities are inconclusive or when the patient of suspected $\mathrm{Rb}$ refuses enucleation [15]. If a case of $\mathrm{Rb}$ is punctured and confirmed by pathology, enucleation must be performed immediatly.

Histopathologic interpretation of the FNAB is crucial, surgeons should be aware that there is an increased risk of misdiagnosis because the small amount of tissue obtained, besides the technology related to sample handling. Ideally liquid-based cytology (ThinPrep ${ }^{\star}$ processing system for ophthalmic FNAB samples). This method is recommended because it optimizes cell yield and preservation and standardizes slide preparation for interpretation in this setting of limited material. Despite liquid-based cytology is available in Mexico, it has not been used yet in the ophthalmic pathology field. Slides processing is done manually adding conservation artifacts and causing overlaping of cells, making more complex and difficult the microscopic interpretation. Routine stains for intraocular FNAB are Papanicolaou, Diff-Quick, HematoxilinEosine and Peryodic Acid Schiff. The cell block initial evaluation is under routine stains and further immunohistochemistry study.

Even with the sinuous panorama regarding intraocular FNAB in Mexico, first results are encouraging. Despite it is not innocuos FNAB in trained hands represents a useful diagnostic media. It is important to know the context that prevails, its scope and limitations in our medical environment.

\section{References}

1. Singh AD, Biscotti CV (2012) Fine needle aspiration biopsy of ophthalmic tumors. Saudi J Ophthalmol 26: 117-123.[Crossref]

2. Jakobiec FA, Coleman DJ, Chattock A (1979)Ultrasonically guided needle biopsy and cytologic diagnosis of intraocular tumors. Ophth AAO 86: 1662-1678.

3. Sahasranamam V (2006) Intraocular "Mass" Lesion a Diagnostic dilemma. Kerala Journal of Ophthamology 18: 249-251. [Crossref]

4. Eide, N, Walaas L (2009) Fine-needle aspiration biopsy and other biopsies in suspected intraocular malignant disease: a review. Acta Ophthalmol 87: 588-601. [Crossref] 
5. De Potter P (1998) Ocular manifestations of cancer. Curr Opin Ophthalmol 9: 100-104. [Crossref]

6. Shanmugam MP, Biswas J (1997) Fine needle aspiration biopsy in the diagnosis of intraocular mass lesions. Indian J Ophthalmol 45: 105-108.[Crossref]

7. Shields CL, Schoenberg E, Kocher K, Shukla SY, Kaliki S, et al. (2013) Lesions simulating retinoblastoma (pseudoretinoblastoma) in 604 cases: results base on age at presentation. Ophthalmology 120: 311-316. [Crossref]

8. Shields JA, Shields CL, Ehya H, Eagle RC, De Potter P (1993) Fine needle aspiration biopsy of suspected intraocular tumors. Ophthalmology 100: 1677-1684. [Crossref]

9. Rishi P, Dhami A, Biswas J (2016) Biopsy techniques for intraocular tumors. Indian J Ophthalmol 64: 415-421. [Crossref]

10. Shields CL, Ganguly A, Materin MA, Teixeira L, Mashayekhi A, et al. (2007) Chromosome 3 analysis of uveal melanoma using fine-needle aspiration biopsy a the time of plaque radiotherapy in 140 consecutive cases: the Deborah Iverson, MD, Lectureship. Arch Ophthalmol 125: 1017-1024. [Crossref]
11. Cohen VM, Dinakaran S, Parsons MA, Rennie IG (2001) Transvitreal fine needle aspiration biopsy: the influence of intraocular lesion size on diagnostic biopsy result. Eye (Lond) 15: 143-147. [Crossref]

12. Faulkner-Jones BE, Foster WJ, Harbour JW, Smith ME, Dávila RM (2005) Fine needle aspiration biopsy with adjunct immunohistochemistry in intraocular tumor management. Acta Cytol 49: 297-308. [Crossref]

13. Char DH, Miller TR (1984) Fine needle biopsy in retinoblastoma. Am J Ophthalmol 97 686-690. [Crossref]

14. Augsburger JJ, Shields JA, Folberg R, Lang W, O'Hara BJ, et al. (1985) Fineneedle aspiration biopsy in the diagnosis of intraocular cancer. Cytologic-histologic correlations. Ophthalmology 92: 39-49. [Crossref]

15. Sen S, Singha U, Kumar H, Ghose S, Sarkar T, et al. (1999) Diagnostic intraocular fine-needle aspiration biopsy-An experience in three cases of retinoblastoma Diagn Cytopathol 21:331-334. [Crossref]

Copyright: (C)2017 Moreno-Páramo D. This is an open-access article distributed under the terms of the Creative Commons Attribution License, which permits unrestricted use, distribution, and reproduction in any medium, provided the original author and source are credited. 